\title{
GPS III Arrived - An Initial Analysis of Signal Payload and Achieved User
} Performance

$\left.\underline{\text { Steffen Thoelert }}{ }^{1}\right)$, Peter Steigenberger ${ }^{2)}$, Oliver Montenbruck ${ }^{2)}$, Michael Meurer ${ }^{1)}$

1) German Aerospace Center - DLR, Institute of Communications and Navigation

2) German Aerospace Center - DLR, German Space Operations Center

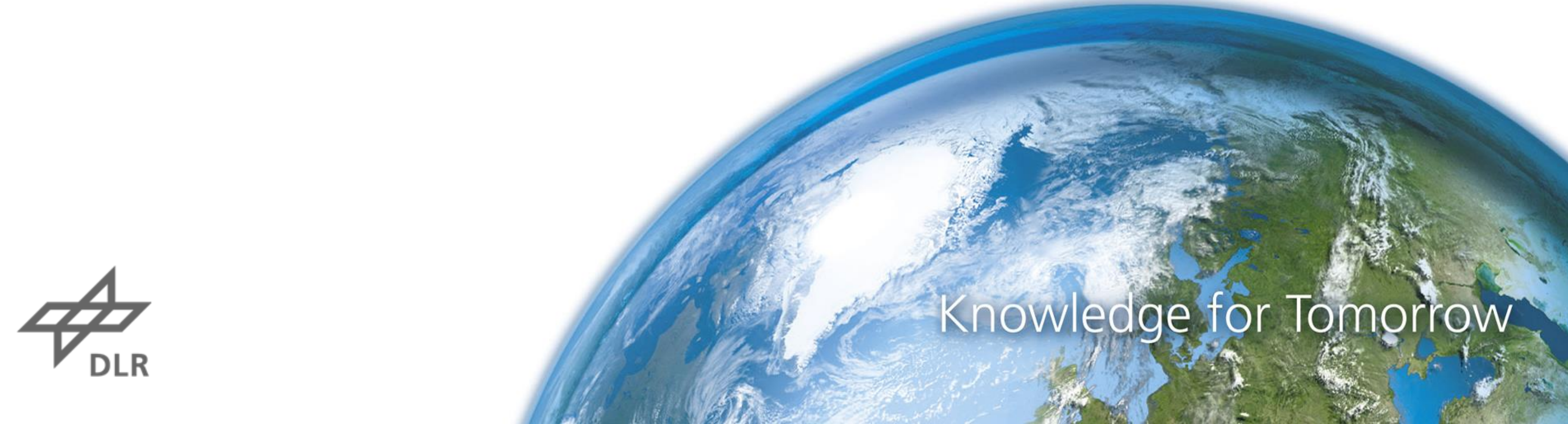




\section{Motivation}

- GPS III-1 (SVN 74) is the first satellite of a new GPS generation

- New signal on board $\rightarrow \mathrm{L} 1 \mathrm{C}$

- Signal quality comparing to previous GPS generations

- From the perspective of the user

- Transmit \& received power over elevation (satellite antenna pattern)

- Signal deformation analysis (L1C, L5)

- First multipath \& noise and clock estimates 


\section{Expectations / ICD}

- Signals onboard of GPS III in L1 band

\begin{tabular}{|l|l|l|l|l|}
\hline Component & Modulation & $\begin{array}{l}\text { Chipping rate } \\
{[\mathrm{MHz}]}\end{array}$ & $\begin{array}{l}\text { Minimum received } \\
\text { power [dBW] }\end{array}$ & Reference \\
\hline C/A & BPSK(1) & 1.023 & -158.5 & IS-GPS-200J (2018) \\
\hline L1C data & BOC(1,1) & 1.023 & -163.0 & IS-GPS-800E (2018) \\
\hline L1C pilot & TMBOC(6,1,4/33) & 1.023 & -158.25 & IS-GPS-800E (2018) \\
\hline P(Y) & BPSK(10) & 10.23 & -161.5 & IS-GPS-200J (2018) \\
\hline M & BOC (10,5) & 10.23 & -158.0 & Marquis and Reigh (2015)
\end{tabular}

- How GPS manages the implementation of an additional signal on L1 band:

- Interplexing: Majority voting of L1C (data+pilot) and $\mathrm{P}(\mathrm{Y})$-code $^{*}$ in In-phase channel and C/A-code on Quadrature channel

- What about M-code?

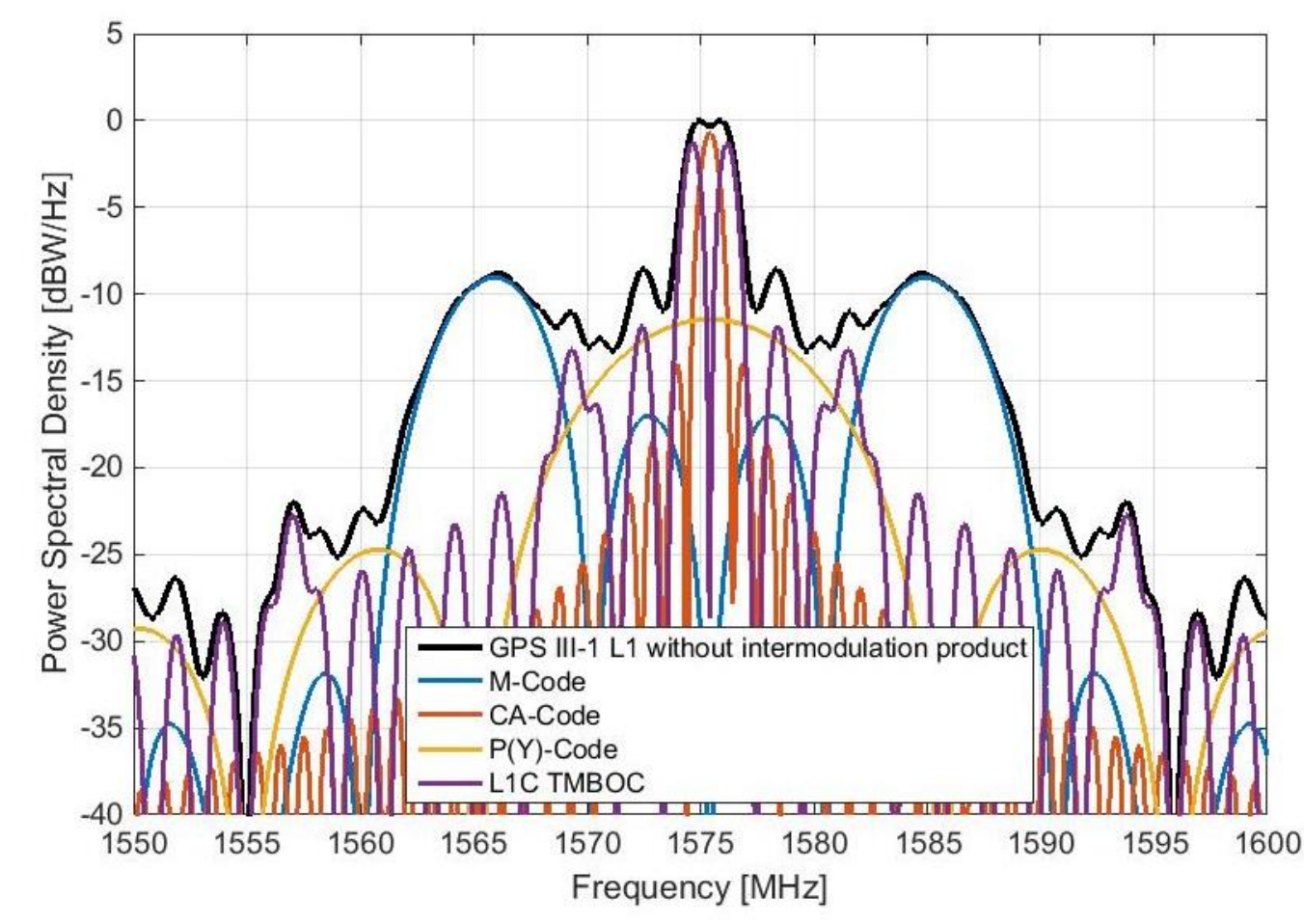

- L2 and L5 signals as known from GPS IIF

${ }^{*}$ Reference: D. Allen et.al. (2019) Effect of GPS III Weighted Voting on P(Y) Receiver Processing Performance. ION ITM 2019, Reston, USA 


\section{Spectral view}

- First signal transmission captured by GNSS receivers on January 9 , 2019

- First spectral overview captured at ground station Weilheim, Germany on January 9, 2019 using a $30 \mathrm{~m}$ dish

- Measured L1 spectrum in comparison with the theory and GPS IIF
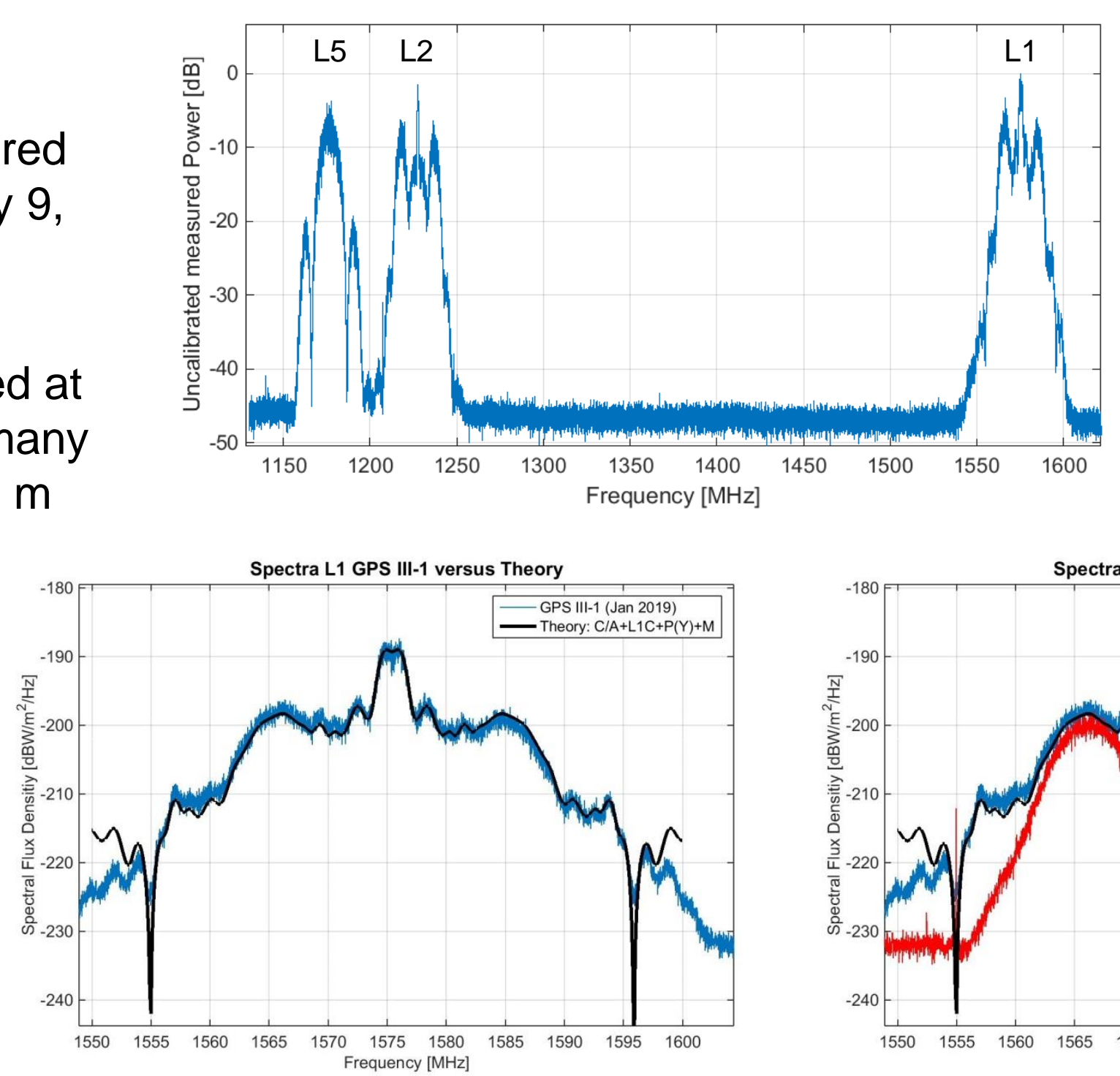

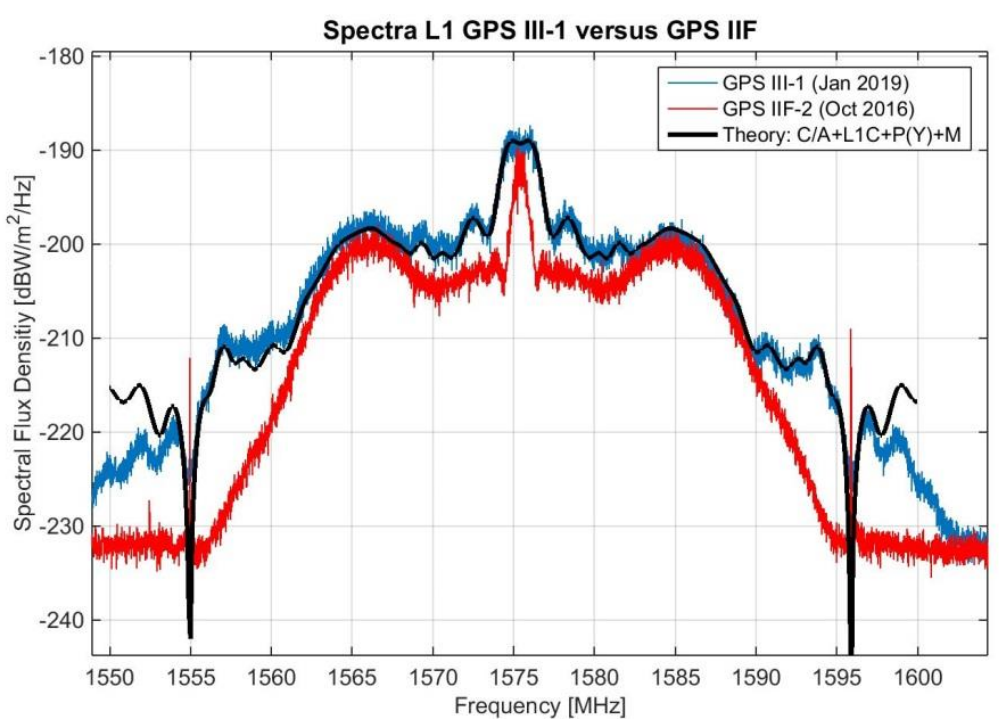




\section{Transmit Power - GPS IIF versus GPS III}

- Equivalent isotropic radiated power (EIRP) measured at Weilheim, Germany

- Considered satellites: GPS III-1 and GPS IIF-2

- Data captured every 5 minutes at Weilheim ground station over a full satellite pass
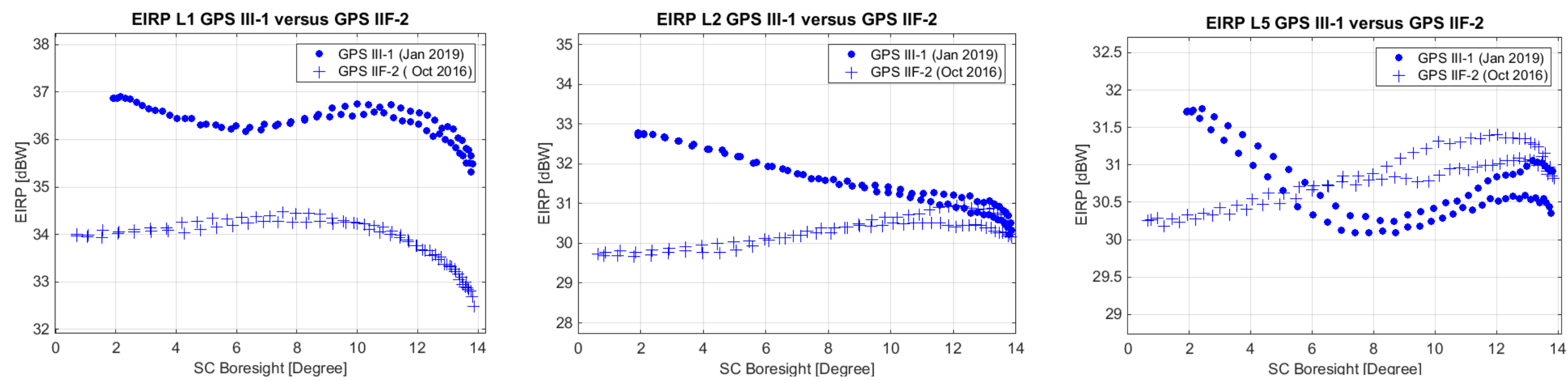

- Different pattern shapes can be observed for all frequency bands. What could be the origin? 


\section{Inphase (I) \& Quadrature (Q) Data Constellation View}

\begin{tabular}{|ccc|}
\hline & GPS III-1 & \\
$\mathrm{L} 1$ & $\mathrm{~L} 2$ & $\mathrm{~L} 5$ \\
\hline
\end{tabular}

\begin{tabular}{|c|}
\hline GPS IIF-1 \\
L5 \\
\hline
\end{tabular}
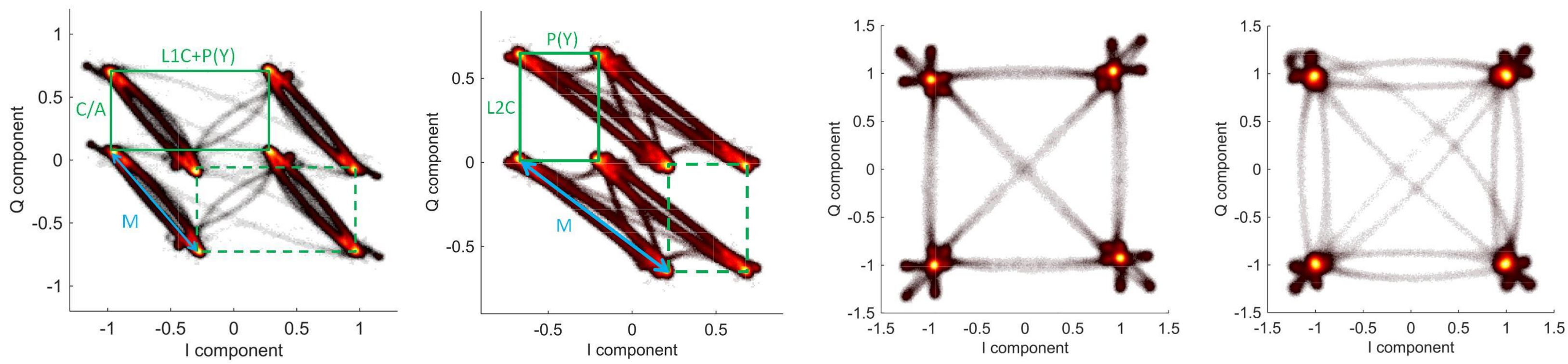

- Constellation plots show good signal quality in terms of possible signal distortions based on their clear constellation points and almost straight chip transitions for GPS III-1. 


\section{Inphase (I) \& Quadrature (Q) Data Constellation View}

- GPS III-1 L1 IQ constellation over measurement time

- M-Code phase relation according to other L1 signals changes over elevation (measurement time)
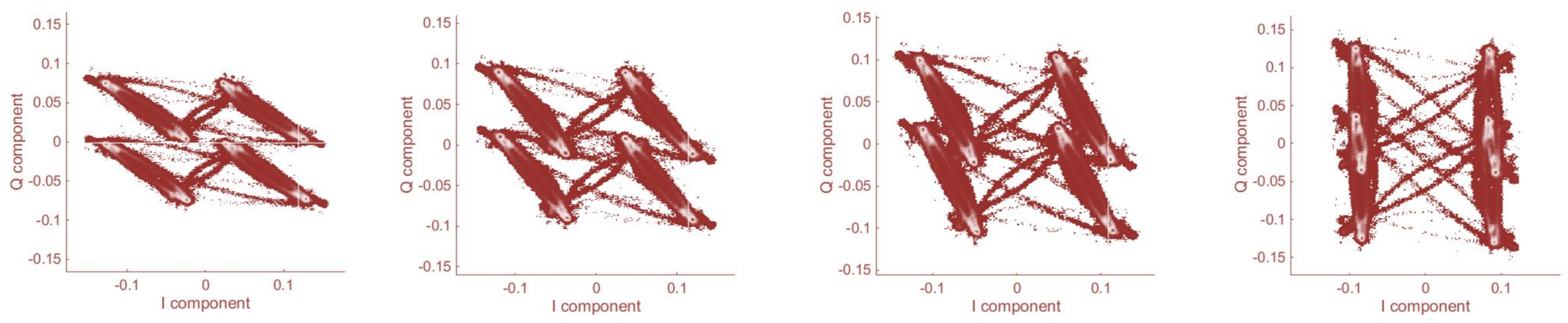

\section{Measurement time}

- Conclusion: M-code transmission not via same antenna network as for the other $L 1$ signals $(C / A, P(Y)+L 1 C)$ 


\section{L1 Gain Patterns of individual Components}

- IQ constellation provides amplitude relation between $\mathrm{C} / \mathrm{A}$-code, $\mathrm{L} 1 \mathrm{C}+\mathrm{P}(\mathrm{Y})$-code and $\mathrm{M}$-code

- Spectra over time provide power relation over time. For separation purposes, one can use a part only with Mcode and another one only with $\mathrm{P}(\mathrm{Y})+\mathrm{L} 1 \mathrm{C}$ respectively $\mathrm{C} / \mathrm{A}$-code (illustrated by the red boxes).

- Combining IQ constellation and transmit power information over time, one can separate gain patterns for $L 1$ $\mathrm{C} / \mathrm{A}-, \mathrm{M}-$ and $\mathrm{L} 1 \mathrm{C}+\mathrm{P}(\mathrm{Y})$ components
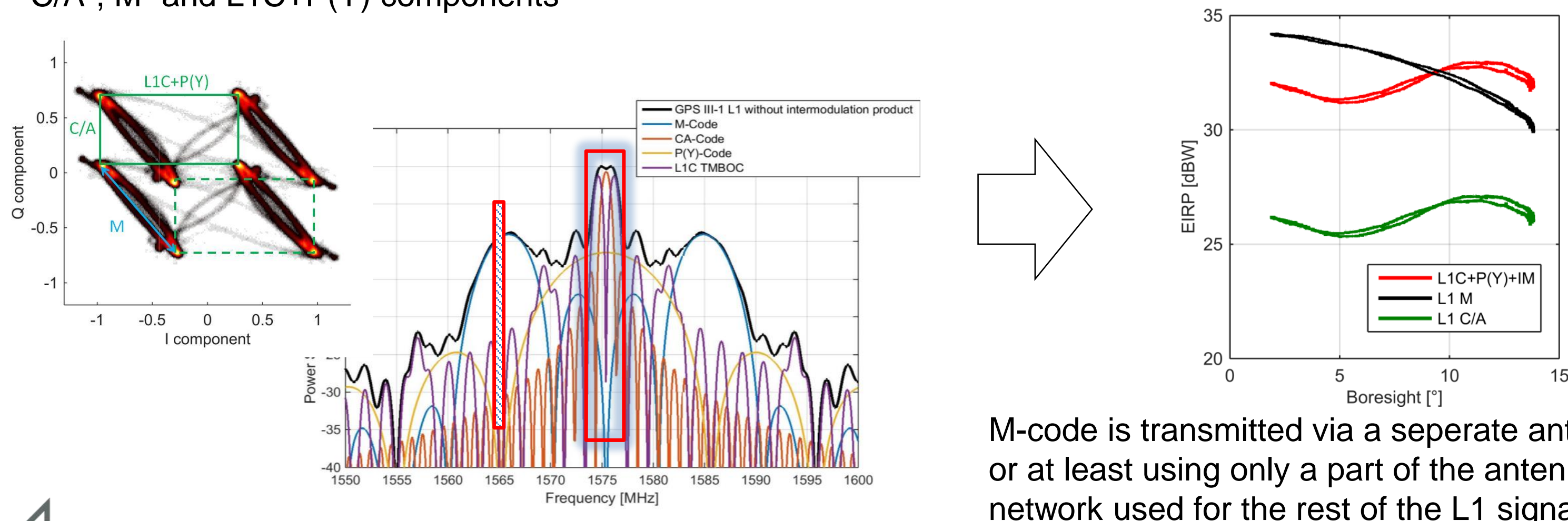

M-code is transmitted via a seperate antenna or at least using only a part of the antenna network used for the rest of the L1 signals 


\section{Transmit Power - GPS IIF versus GPS III}

- Conclusions of IQ constellation and power spectra analysis regarding transmit pattern of GPS III:

- L1: Superposition of $C / A+P(Y)+L 1 C$ antenna network and M-code antenna network with different gain patterns

- L2: Superposition of $P(Y)+L 2 C$ antenna network and M-code antenna network with different gain patterns

- L5: Seems to be a new antenna
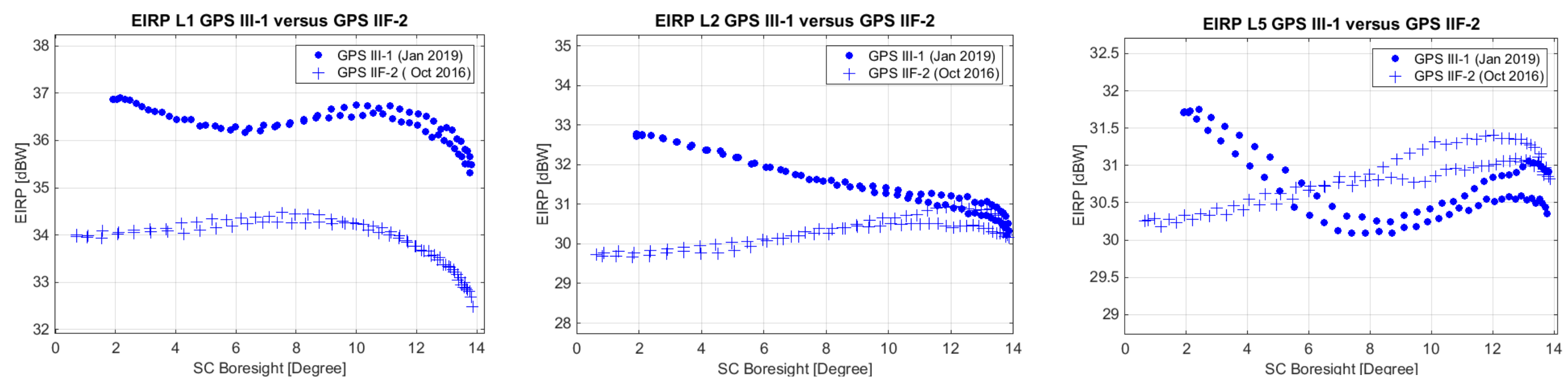

-What does the transmitted power mean for users and their signal strength reception? 


\section{Signal strength from the perspective of the user}

- Carrier-to-noise density ratio of GPS signals tracked by a Septentrio PolaRx5 receiver with a Leica AR1203+GNSS antenna in Oberpfaffenhofen, Germany.
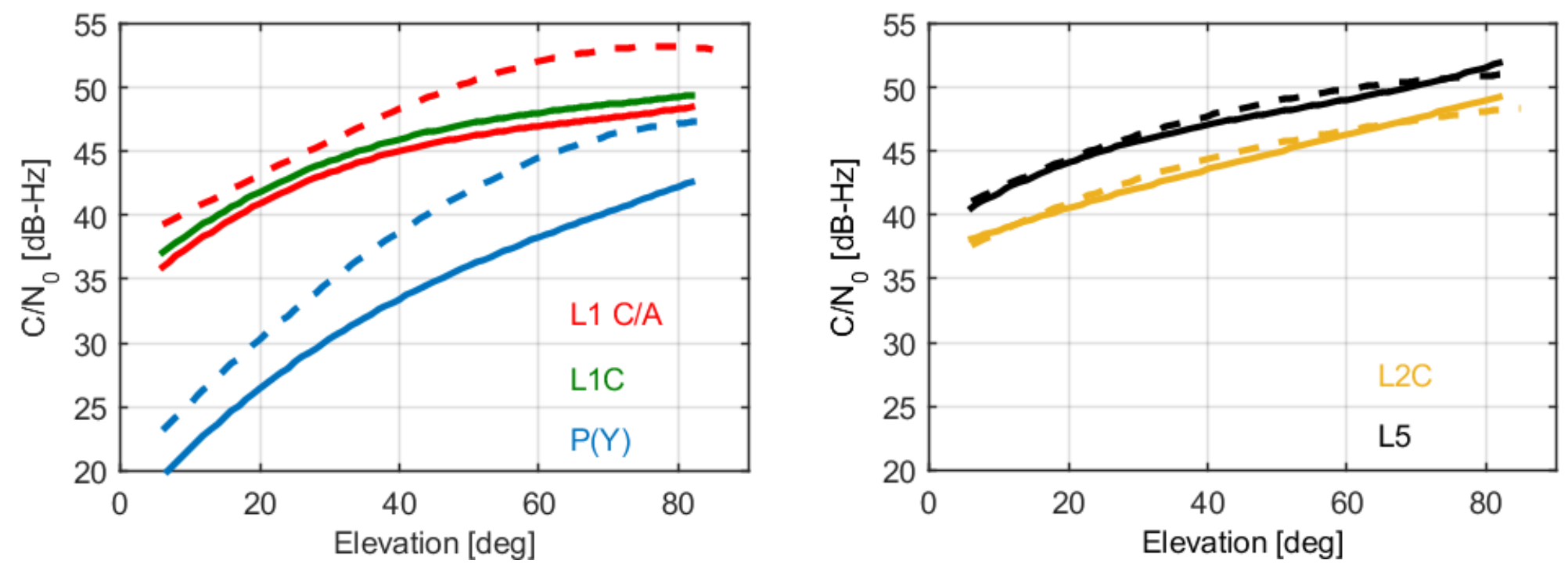
Legend:
GPS III-1 (solid line)
E=E GPS Block IIF satellite (SVN 68, dashed line)

- Measured minimum received power for L1 C/A-code of $-157.9 \mathrm{dBW}$ at $5^{\circ}$ elevation (ICD $-158.5 \mathrm{dBW}$ ) 


\section{Signal Deformation \& Differential Code Bias Estimation: L1 band}

- Performance of the new GPS L1C signal in differential GNSS applications, like Ground Based Augmentation Systems (GBAS)

- Differential code bias estimation GPS III-1 L1C versus Galileo E1C based on S-curve bias method GPS III-1

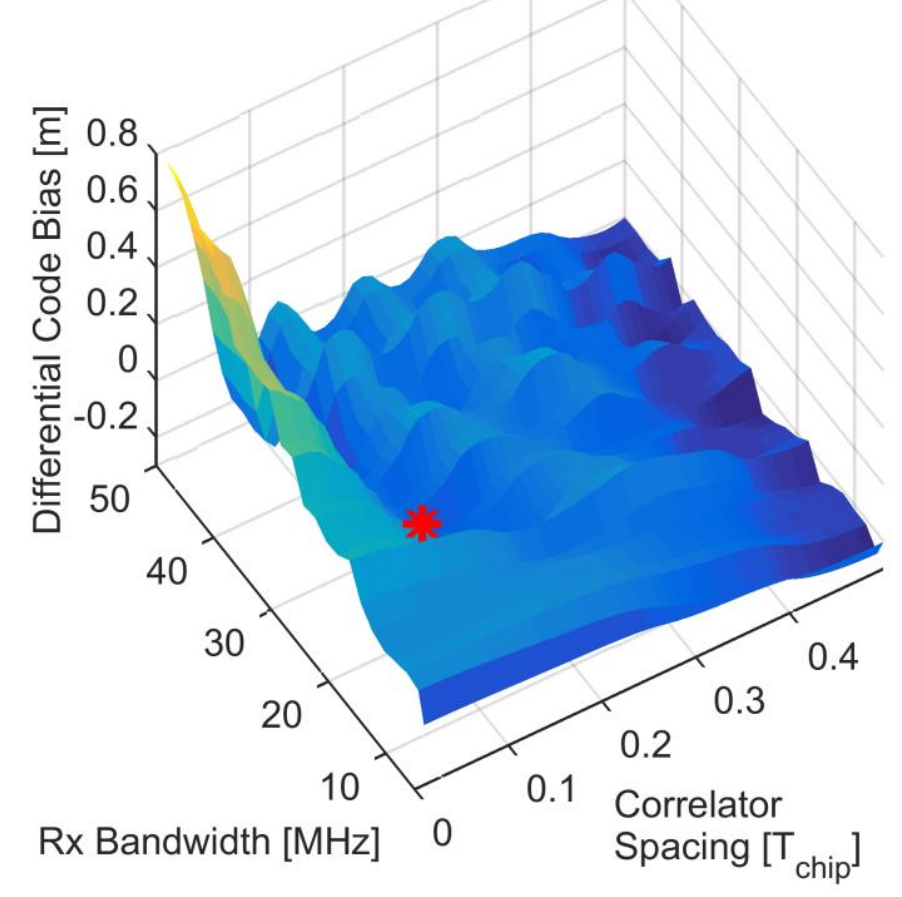

* Reference Receiver settings based on the current draft MOPS for aviation applications:

Spacing $=0.1 \mathrm{chip}$ Bandwidth $=24 \mathrm{MHz}$
GSAT 0209

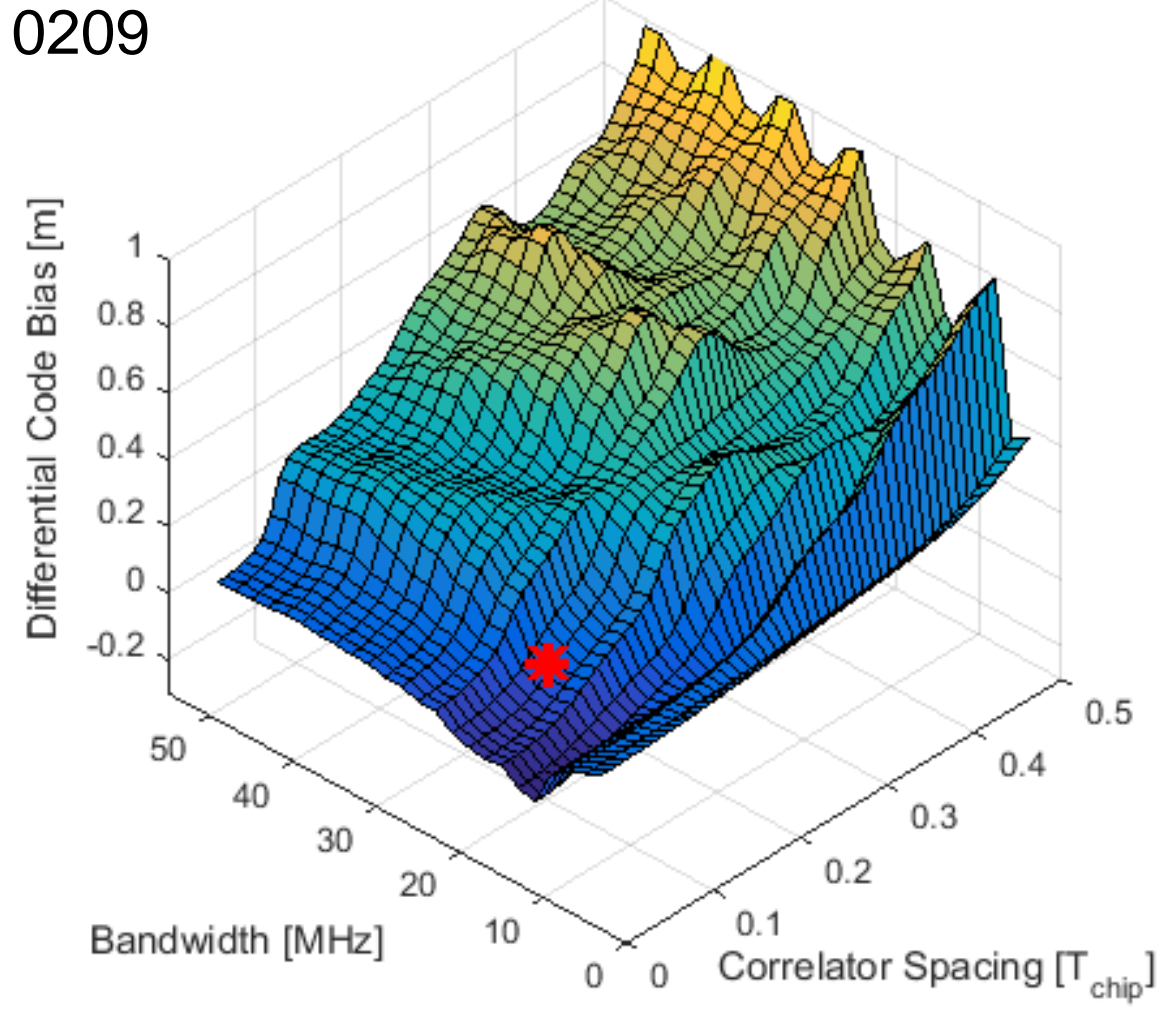




\section{Signal Deformation \& Differential Code Bias Estimation: L5 band}

- Differential code bias estimates for GPS III-1 versus GPS IIF-1 for L5 pilot

\section{GPS III-1}

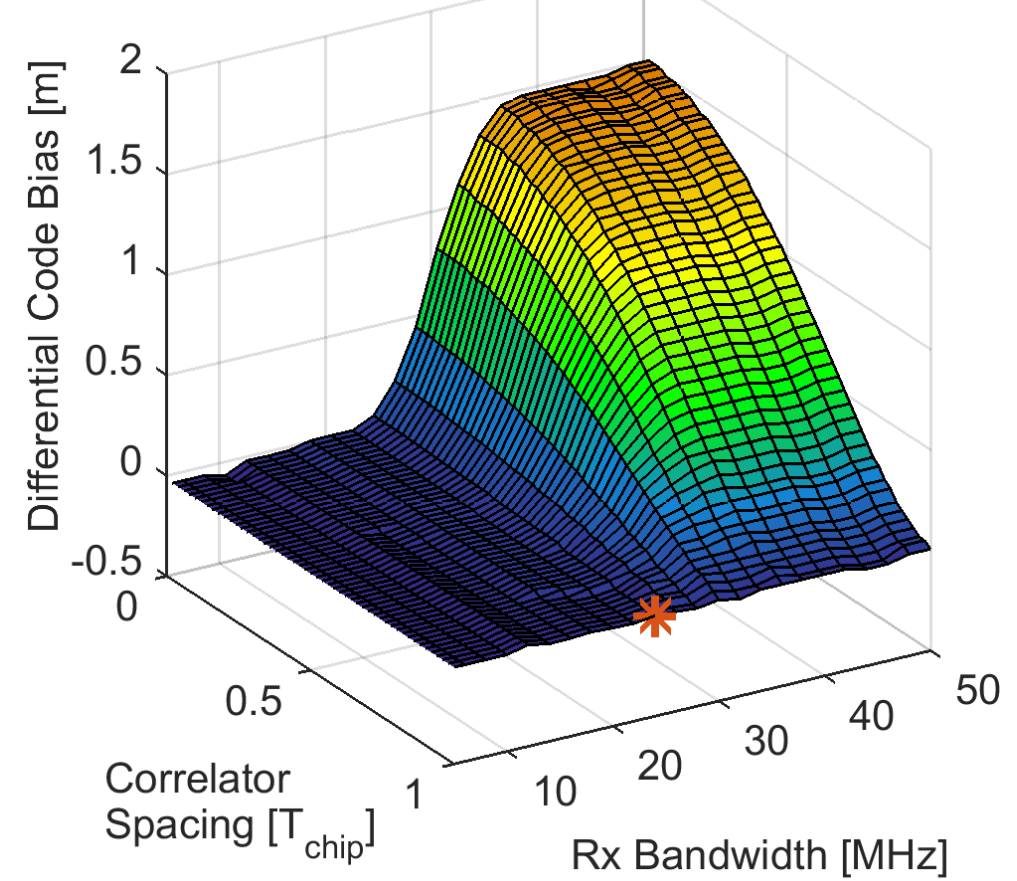

\section{GPS IIF-1}

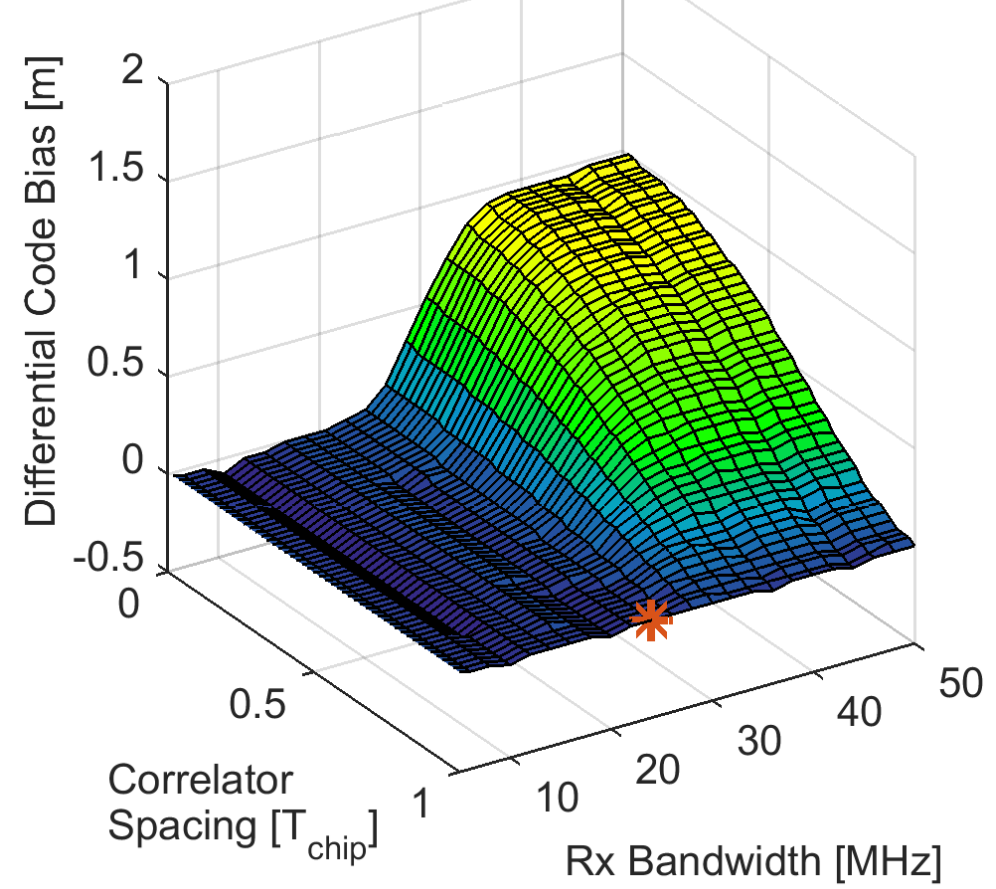

\begin{tabular}{|l|c|c|} 
& $\begin{array}{r}\text { Digital distortions } \\
\text { [ns] }\end{array}$ \\
\hline Signal & GPS IIF-1 & GPS III-1 \\
\hline L5 data & 5.1 & 0.2 \\
\hline L5 pilot & 3.6 & 0.4 \\
\hline
\end{tabular}

* Reference Receiver settings based on the current draft MOPS for aviation applications:

Spacing $=1$ chip

Bandwidth $=24 \mathrm{MHz}$

- Very low differential biases up to $25 \mathrm{MHz}$ input bandwidth and a wide range of correlator spacing for both GPS satellites 


\section{Receiver Tracking: Multipath \& Noise}

- Multipath \& noise estimation based on Javad TR_3 receiver data from IGS station (POTSO0DEU) at Potsdam, Germany

GPS III-1 (G04)

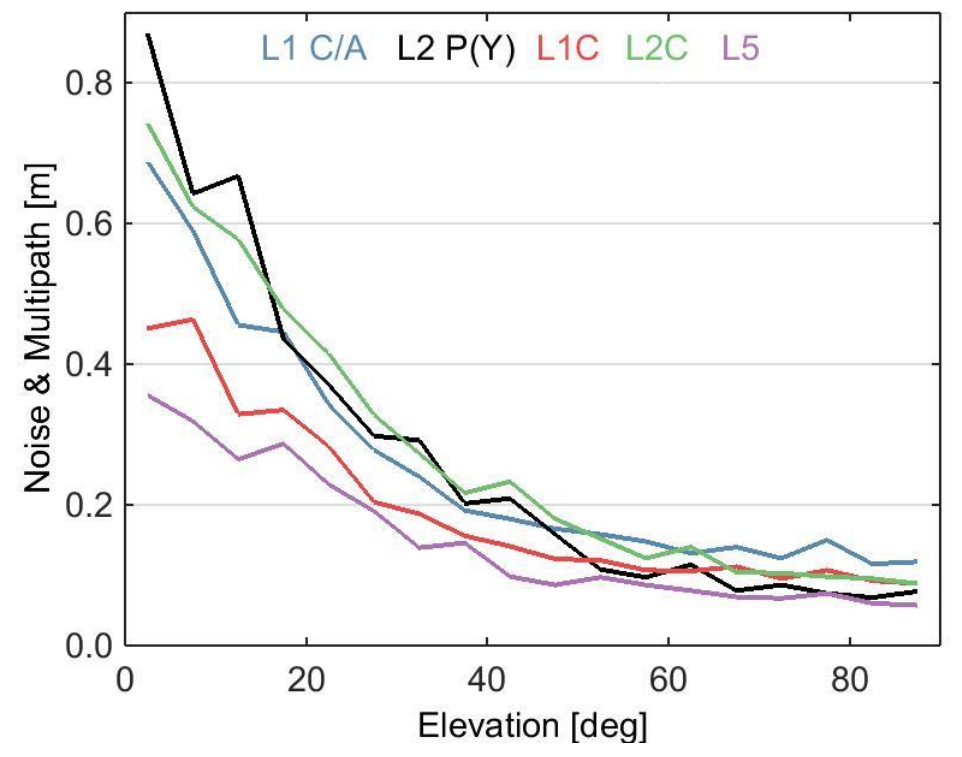

GPS IIF-7 (G09)

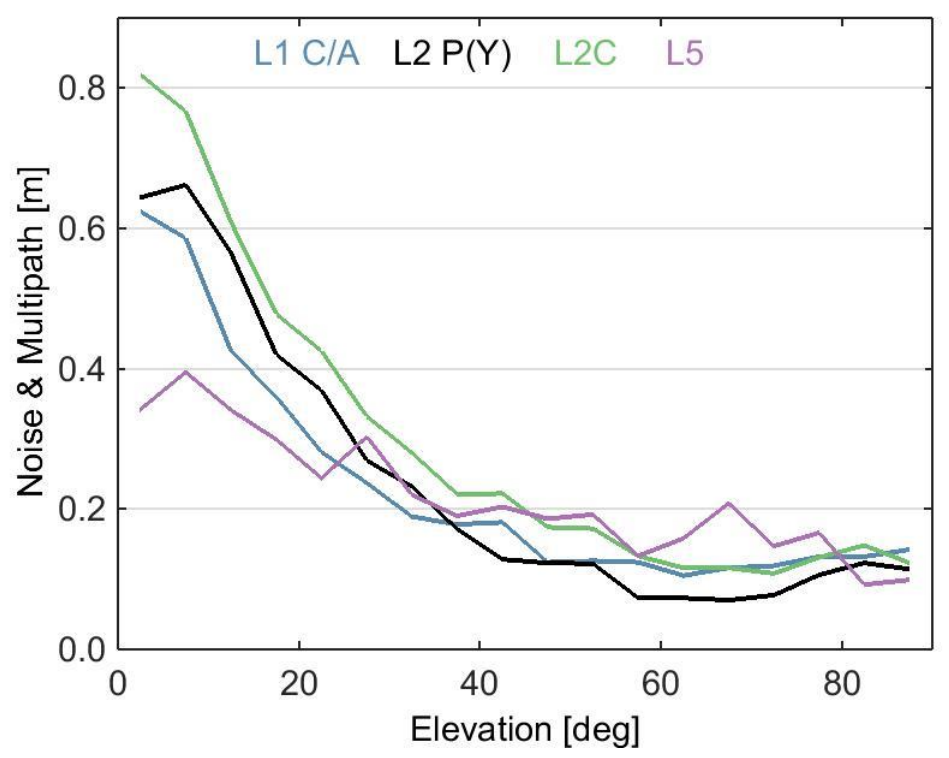

- Multipath combination

$\operatorname{MP}\left(p_{i}, \varphi_{i}, \varphi_{j}\right)=p_{i}-\varphi_{i}-2 \frac{f_{j}^{2}}{f_{i}^{2}-f_{j}^{2}}\left(\varphi_{i}-\varphi_{j}\right)$

$p_{i}$ pseudorange observations $\varphi_{i}, \varphi_{j}$ carrier phase observations

$i, j$ frequency index: $i, j=1,2,5$

- RMS in 5 deg elevation bins 


\section{Interfrequency Clock Bias (IFCB)}

- Interfrequency clock bias estimation based on triple carrier phase observations using measurements of 7 stations

- For lower elevations the triple carrier phase combination is dominated by noise and multipath

- Results:

- Block IIF: small orbit-periodic variations can be seen for the Block IIF satellite (within cm-range, peak-to-peak approx. $4 \mathrm{~cm})$

- Block III: no orbit periodic variations

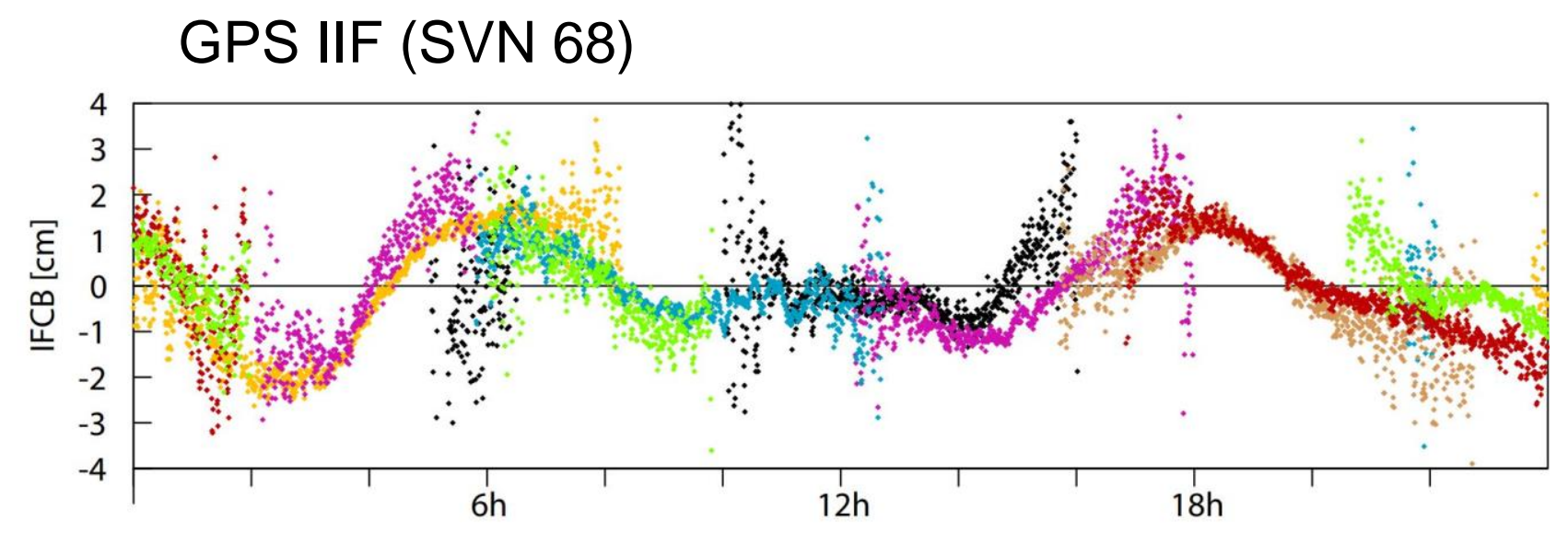

GPS III (SVN 74)

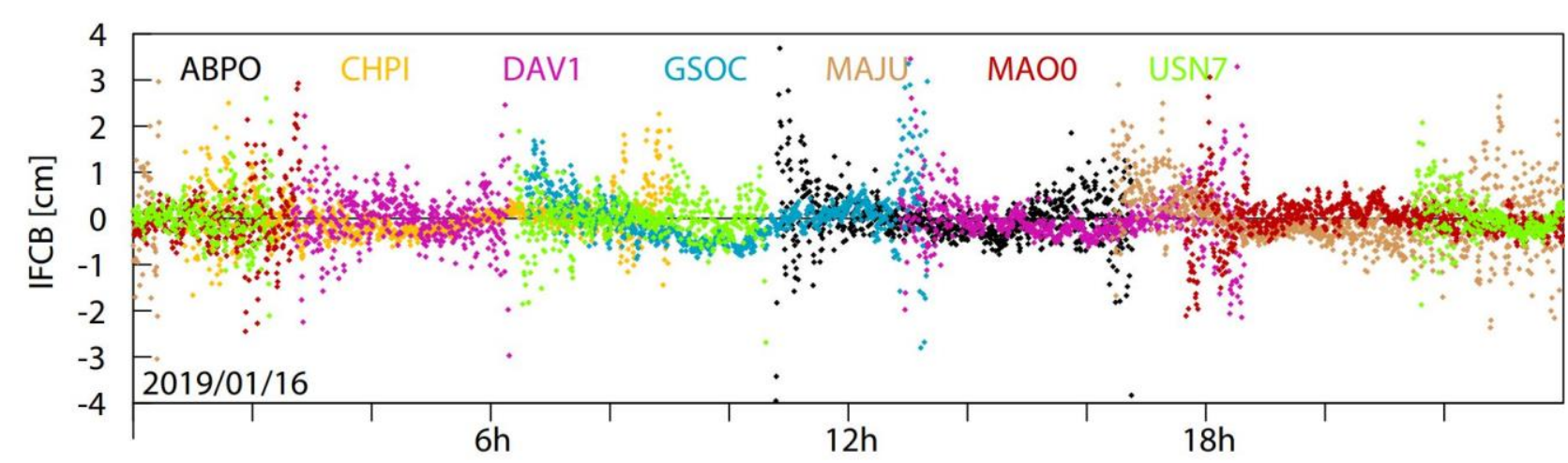




\section{GPS III-1 current signal status (August 2019)}

- Reduced transmit power on all 3 bands
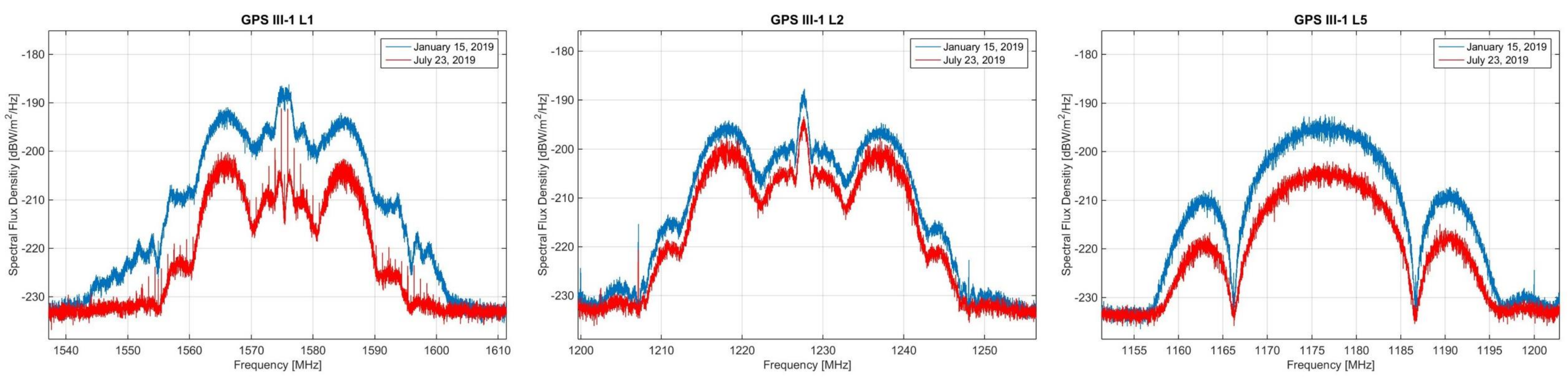

- Instead of nominal C/A-code the non-standard code is transmitted on L1

- L1C PRN moved from 4 to 117, L5 PRN has also moved

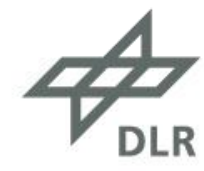




\section{Conclusion and Outlook}

- The new GPS III generation has started signal transmission

- The new signal L1C is present and shows good quality in terms of signal distortions and noise \& multipath characteristics

- M-code transmission is partially separated from other signals on L1 and L2

- Minimum received power for $\mathrm{L} 1 \mathrm{C} / \mathrm{A}$-code is in line with $\mathrm{ICD}$, but with low margin to its proposed minimum

- L5 signal has comparable signal distortions to GPS IIF block satellites

- Good consistency of L1/L2/L5 carriers, no signs of orbit dependent interfrequency bias variations

- Currently the GPS III-1 uses non-operational signal transmission 

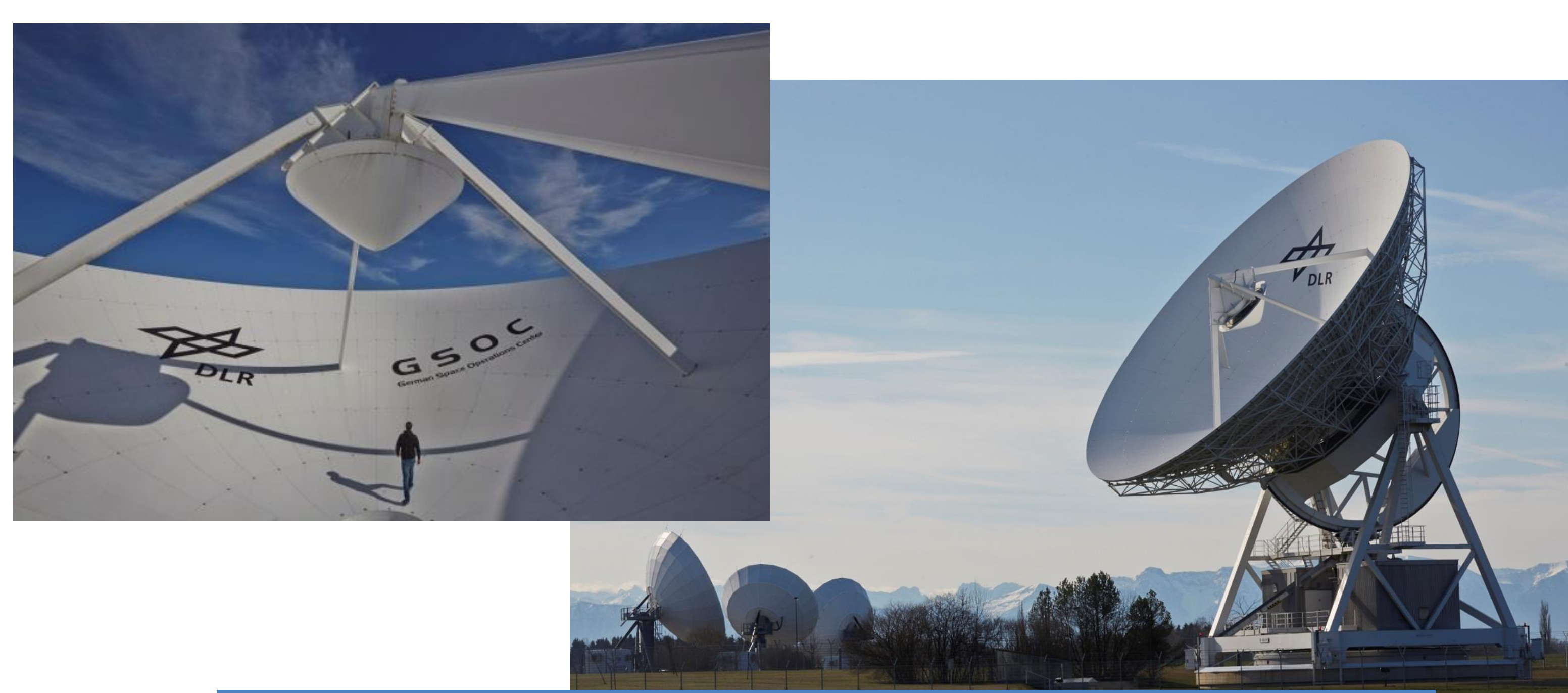

Thank you for your attention - Any questions? 